\title{
Strategi Bersaing Dalam Meningkatkan Kinerja Perusahaan Pada Bisnis Jasa Perhotelan
}

\author{
Eka Setiajatnika dan Muhamad Ardi Nupi Hasyim \\ Institut Manajemen Koperasi Indonesia \\ ekasetiajatnika@ikopin.ac.id
}

\begin{abstract}
ABSTRAK
Penelitian tentang Strategi Bersaing Dalam Meningkatkan Kinerja Perusahaan Pada Bisnis Jasa Perhotelan menyoroti tentang bagaimana perusahaan mencapai daya saing dan peningkatan kinerja perusahaan. Dalam menjalankan usahanya perusahaan Hotel XYZ menghadapi masalah, yaitu penurunan jumlah kunjungan tamu dan lemahnya daya saing perusahaan. Penelitian ini menggunakan metode kualitatif dengan menggunakan pendekatan deskriptif. Untuk pengumpulan data metode yang digunakan adalah dengan cara memberikan kuesioner kepada pelanggan hotel dan wawancara kepada informan yang kemudian menganalisis data tersebut berdasarkan matrik IFE dan EFE. Berdasarkan hasil penelitian ditemukan bahwa Level perusahaan saat ini menandakan bahwa Hotel XYZ masih berada di tingkat rata-rata, sehingga hotel XYZ harus membuat strategi yang baik agar kedepannya perusahaan dapat mencapai visi serta misi perusahaan. Berdasarkan analisis IFE dan EFE Hotel XYZ berada pada kuadran lima sehingga strategi yang dapat dilakukan oleh Hotel XYZ untuk meningkatkan daya saing perusahaan dengan melakukan persaingan melalui diferensiasi.
\end{abstract}

Kata Kunci : Perusahaan, Bisnis Jasa Perhotelan

\section{ABSTRACT}

Research on Corporate Competitive Strategies in Increasing Number of Guest Visits In The Hospitality Business (Case Study At Four Star XYZ Hotel in Tangerang City,) highlights how the company achieves competitiveness and improves its performance. In running its business Hotel XYZ faced problems, namely decreasing the number of guest visits and weak competitiveness of the company. This research used qualitative method by using descriptive approach. For data collection method used is by giving questionnaires to hotel customers and interviews to informants who then analyze the data based on the IFE and EFE matrix. Based on the research results found that the current level of company indicates that XYZ Hotel is still in the average level, so XYZ hotel should make a good strategy for the future the company can achieve the vision and mission of the company. Based on the analysis of IFE and EFE Hotel XYZ is in quadrant five so that strategy can be done by Hotel XYZ to improve the competitiveness of company by doing competition through differentiation.

Keyword: Hospitality Services Business

\section{PENDAHULUAN}

Peningkatan daya saing dan perbaikan kinerja memerlukan sebuah metode yang dapat digunakan oleh perusahaan agar menjadi world class company of customer choice. Demirbag et al. (2006) mengatakan Kinerja Perusahaan akan menghasilkan kemampuan kompetitif jika pelaksanaan peningkatan daya saing dapat dilakukan dengan baik seperti memahami kebutuhan pelanggan, meningkatkan kepuasan pelanggan dan komunikasi internal. Bisnis Jasa perhotelan merupakan industri yang unik dimana perusahaan hotel yang memiliki kinerja baik akan menjadi pilihan pelanggan untuk menggunakan jasa akomodasi, sehingga bisa dilihat semakin banyak jumlah kunjungan tamu hotel maka perusahaan hotel telah menerapkan kinerja perusahaan dengan baik.
Hotel XYZ merupakan salah satu hotel berbintang empat di Kota Tangerang. Berdasarkan observasi di lapangan dan Manager Front Office, Hotel yang dibangun pada tahun 2012 memiliki karakteristik berbeda dan unik, dimana jumlah kamar tidak terlalu banyak bertujuan agar perhatian dan pelayanan kepada para tamu dapat lebih maksimal. Keunikan ini memberikan peluang besar bagi Hotel XYZ untuk menguasai pasar di Kota Tangerang, dimana tamu akan membayar harga tinggi untuk mendapatkan pelayanan terbaik. Peningkatan kinerja akan terus dikembangkan guna memberikan pengalaman luar biasa kepada pelanggan. Hotel XYZ memiliki beberapa pesaing cukup kuat pada saat ini. Pesaing utama yang diperhitungkan oleh Hotel XYZ adalah Novotel Hotel, Hotel Istana Nelayan, Hotel Narita, dan FM7 
Hotel. Tabel 1. menunjukan jumlah pesaing dan kepemilikan kamar Hotel XYZ.

Hotel XYZ mencatat jumlah kunjungan tamu yang dapat dilihat pada tabel 1 :

Tabel 1. Jumlah Kunjungan Tamu di Hotel Bintang Empat XYZ Tangerang dari Periode Januari - September 2017

\begin{tabular}{|c|c|c|}
\hline Bulan & Tamu Asing & $\begin{array}{c}\text { Tamu } \\
\text { Domestik }\end{array}$ \\
\hline Januari & 5 & 2.149 \\
\hline Februari & 12 & 2.118 \\
\hline Maret & 10 & 2.001 \\
\hline April & 9 & 1.987 \\
\hline Mei & 6 & 1.996 \\
\hline Juni & 10 & 2.150 \\
\hline Juli & 15 & 2.111 \\
\hline Agustus & 10 & 2.135 \\
\hline September & 5 & 2.120 \\
\hline
\end{tabular}

Sumber :Hotel XYZ Kota Tangerang, 2017

Kunjungan tamu asing di hotel XYZ sampai dengan bulan September 2017 sebanyak 82 orang, jumlah tersebut mengalami penurunan sebesar $79 \%$ dari tahun 2016, lebih lanjut dapat dilihat jumlah kunjungan tamu domestik hotel XYZ sampai dengan bulan September 2017 sebesar 18.767 orang jika dibandingkan dengan jumlah kunjungan tamu domestik pada tahun 2016 mengalami penurunan sebesar $25 \%$.

Peningkatan daya saing dan jumlah kunjungan tamu merupakan dua masalah yang harus dihadapi oleh hotel XYZ, Perusahaan hotel harus menggunakan pengukuran kinerja berdasarkan kriteria agar dapat digunakan sesuai dengan kebutuhan perusahaan, tidak hanya melihat dari aspek finansial dan produksi saja, tetapi harus dinilai dari organisasi secara keseluruhan. Penilaian kinerja Hotel XYZ saat ini hanya sebatas melakukan pengukuran dari aspek keuangan dan belum melakukan penilaian secara keseluruhan, sehingga diperlukan sebuah metode pengukuran kinerja yang lebih efisien dan kompetitif. Metode pengukuran kinerja dari segala aspek diperlukan untuk melakukan evaluasi terhadap performa hotel XYZ, sehingga hasil akhirnya dapat memenuhi harapan perusahaan agar dapat memenangkan persaingan dan meningkatkan jumlah kunjungan tamu hotel di masa mendatang.

\section{TINJAUAN PUSTAKA}

\section{Kinerja Perusahaan}

Kinerja perusahaan hendaknya merupakan hasil yang dapat diukur dan menggambarkan kondisi empirik dari berbagai ukuran standar perusahaan. Menurut Nasucha kinerja perusahaan sebagai efektivitas organisasi secara menyeluruh untuk memenuhi kebutuhan setiap kelompok yang berkenaan dengan usaha secara sistematik dalam meningkatkan kemampuan organisasi secara terus menerus dan mencapai kebutuhannya secara efektif (Fahmi, 2013:3). Perusahaan memiliki tujuan untuk menerapkan konsep kinerja perusahaan secara berkualitas dan professional, maka harus dipahami yang menjadi tujuan dari kinerja perusahaan. Tujuan spesifik kinerja perusahaan adalah menciptakan suatu budaya dimana individu dan kelompok bertanggung jawab atas kelanjutan peningkatan proses bisnis, keterampilan dan kontribusi terhadap perusahaan.

Helfert (1996:67) mengatakan kinerja perusahaan adalah sebuah hasil yang dibuat oleh pihak manajemen secara terus menerus. Dalam hal ini, hasil dimaksud merupakan hasil dari keputusan banyak individu. Menurut Moerdiyanto (2010) kinerja perusahaan adalah hasil dari serangkaian proses bisnis dengan pengorbanan berbagai macam sumber daya, yakni sumber daya manusia dan keuangan perusahaan. Apabila kinerja perusahaan meningkat, bisa dilihat dari gencarnya kegiatan perusahaan dalam rangka menghasilkan keuntungan sebesar-besarnya. Keuntungan yang dihasilkan tentu akan berbeda tergantung dengan ukuran perusahaan.

Tujuan penilaian kinerja adalah memotivasi personal dalam mencapai sasaran organisasi dan mematuhi standar agar membuahkan tindakan serta hasil yang diinginkan oleh organisasi. Penilaian kinerja dilakukan guna perbaikan organisasi secara berkesinambungan, karena bagi setiap organisasi khususnya organisasi bisnis merupakan suatu keharusan. Hal ini dilihat dari tingginya persaingan antar perusahaan. Penilaian kinerja diperlukan agar terciptanya peningkatan kualitas kinerja dan pengaruhnya lebih jauh pada peningkatan produktivitas serta profit perusahaan. Tujuan lain penilaian kinerja bagi semua pihak adalah agar mereka mengetahui manfaat yang mereka harapkan (Rivai dan Basri, 2004:55).

\section{Strategi Bersaing}

Heizer (2015:33) mengatakan bahwa perusahaan dapat memperoleh keunggulan kompetitif melalui tiga cara, yaitu :

\section{Bersaing dalam diferensiasi}

Diferensiasi berhubungan dengan penyajian suatu keunikan. Diferensiasi diartikan melampaui ciri fisik dan atribut jasa dengan mencangkup keseluruhan mengenai produk atau jasa yang mempengaruhi nilai dimana konsumen dapatkan.

2. Bersaing dalam biaya

Kepemimpinan biaya rendah berarti mencapai nilai maksimum sebagaimana yang diinginkan 
pelanggan. Hal ini membutuhkan pengujian sepuluh keputusan manajemen operasi dengan usaha keras untuk menurunkan biaya dan tetap memenuhi nilai harapan pelanggan. Strategi biaya rendah tidak berarti nilai atau kualitas barang menjadi lebih rendah.

3. Bersaing dalam respon

Keseluruhan nilai yang terkait dengan pengembangan dan pengantaran barang harus dilakukan dengan tepat waktu, penjadwalan dapat diandalkan dan kinerja yang fleksibel.

Untuk menganalisis bagaimana bahwa perusahaan dapat memperoleh keunggulan kompetitif dapat dilakukan dengan menggunakan matriks IFE (Internal Factor Evaluation) dan EFE (Eksternal Factor Evaluation. Khusus dalam hal analisis data untuk matriks IFE dan EFE maka penulis mengacu kepada teori yang dikemukan oleh Hunger dan Wheelen (2001), yakni dilakukan dengan urutan proses analisis sebagai berikut :

1. Melakukan identifikasi dan menuliskannya pada kolom 1, tentang kekuatan dan kelemahan hotel XYZ dengan kriteria Malcolm Baldrige.

2. Menetapkan bobot dari masing-masing faktor pada kolom 2, mulai dari 1,0 (paling penting) sampai 0,0 (tidak penting). Total semua bobot harus berjumlah 1,0. Semakin besar bobotnya, maka semakin besar prioritas faktor tersebut bagi Hotel XYZ.

3. Menetapkan tingkat peringkat dalam kolom 3 untuk setiap faktor dengan angka 4 (baik), 3 (ratarata), 2 (dibawah rata-rata), 1 (buruk).

4. Setiap peringkat adalah penelitian analisis tentang seberapa baik Hotel XYZ merespon dan mengatasi setiap faktor internal.

5. Kalikan masing-masing bobot dengan peringkatnya untuk memperoleh skor terbobot yang akan ditulis dikolom 4.

6. Tambahkan seluruh skor terbobot sehingga diperoleh total skor terbobot kemudian hasilnya pada baris terakhir kolom ke 4. Total skor terbobot memiliki interval dari angka 4,0 (baik sekali) sampai 1,0 (buruk).

Lebih lanjut untuk melakukan Analisa faktor eksternal perusahaan (EFE) berdasarkan analisa pasar, perusahaan pesaing, keadaan sosial dan pemerintah, pelanggan, dan perekonomian, maka diketahui peluang dan ancaman yang ada di perusahaan. yakni dilakukan dengan urutan proses analisis sebagai berikut :

1. Melakukan identifikasi dan menuliskannya pada kolom 1, tentang peluang dan ancaman pada Hotel XYZ.
2. Menetapkan bobot dari masing-masing faktor pada kolom 2, mulai dari 1,0 (Paling penting) sampai 0,0 (tidak penting). Total semua bobot harus berjumlah 1,0. Semakin besar bobotnya, semakin besar prioritas faktor tersebut bagi perusahaan hotel XYZ.

3. Menetapkan tingkat peringkat dalam kolom 3 untuk setiap faktor dengan angka 4 (baik), 3 (ratarata), 2 (dibawah rata-rata), 1 (buruk). Setiap peringkat adalah penelitian analisis tentang seberapa baik Hotel XYZ mampu merespon dan mengatasi setiap faktor eksternal.

4. Kalikan masing-masing bobot dengan peringkatnya untuk memperoleh skor terbobot yang akan ditulis dikolom 4.

5. Tambahkan seluruh skor terbobot sehingga diperoleh total skor terbobot kemudian hasilnya pada baris terakhir kolom ke 4. Total skor terbobot memiliki interval dari angka 4,0 (baik sekali) sampai 1,0 (buruk).

\section{METODE PENELITIAN}

Penelitian ini menggunakan metode penelitian kualitatif dengan menggunakan pendekatan deskriptif. Untuk pengumpulan data metode yang digunakan adalah dengan cara memberikan kuesioner kepada pelanggan hotel dan informan yang kemudian menganalisis data tersebut berdasarkan matrik IFE dan EFE.

\section{HASIL DAN PEMBAHASAN}

\section{Gambaran Umum Lokasi Penelitian}

Hotel XYZ terletak di area pusat bisnis Kota Tangerang, Banten. Hotel yang berdiri pada tahun 2012. Hotel XYZ memiliki visi menjadikan pemimpin hotel di Kota Tangerang, sedangkan misi Hotel XYZ adalah memberikan produk dan layanan yang bermutu tinggi guna memenuhi harapan pelanggan melalui pengembangan sumber daya dan manajemen yang terbaik. Hotel XYZ memiliki nilai-nilai perusahaan yang harus dijalankan oleh setiap karyawannya, nilai perusahaan tersebut adalah integritas, komitmen, tanggung jawab, dan team work.

Jumlah kamar yang dimiliki oleh Hotel XYZ sebanyak 290 kamar. Setiap kamar dibagi menjadi 4 kualifikasi kamar, yaitu superior twin dua tempat tidur, superior queen satu tempat tidur, family room tiga tempat tidur, dan family room dua tempat tidur. Kamar Hotel XYZ dilengkapi interior serta perabotan modern yang nyaman, Fasilitas masingmasing kamar adalah AC, TV layar datar, kamar mandi, fasilitas balkon tersendiri, minibar di dalam kamar, dan akses wifi pada setiap kamar, sehingga Hotel XYZ dapat mewujudkan aspirasi dan gaya hidup glamor di Kota Tangerang. 
Lokasi berdekatan dengan akses tol menuju bandara Soekarno-Hatta dan pelabuhan merak, membuat hotel XYZ sangat mudah untuk dijangkau, selain itu kemewahan Hotel XYZ dengan kualifikasi bintang empat dilengkapi dengan berbagai fasilitas penunjang, yaitu: kolam renang, spa, fitness center yang terletak di dalam satu area hotel. Penggunaan fasilitas diberikan secara gratis kepada tamu hotel selama bermalam di Hotel XYZ.

Gambaran tentang alur kerja proses pelayanan tamu yang dilakukan oleh Hotel XYZ dimulai dari tamu melakukan check-in, makan di restaurant sampai dengan tamu check-out. Setiap tahapan proses tersebut dilakukan oleh bagian yang berbeda, dimulai dari bagian front office untuk proses data tamu, dilanjutkan ke bagian housekeeping untuk melakukan pembersihan kamar, lalu ke bagian kasir untuk melakukan pembayaran atas kamar yang digunakan, sehingga tamu dapat check-out dari hotel.

\section{Hasil Penelitian}

Dalam rangka memenangkan daya saing perusahaan hotel maka dibutuhkan sebuah strategi yang dapat memanfaatkan kesempatan dan kelebihan, menetralkan ancaman, dan menghindari kelemahan, sehingga diperlukan sebuah metode yang dikenal dengan analisis SWOT (Kekuatan, Kelemahan, Peluang dan Ancaman). Analisis SWOT merupakan sebuah peninjauan formal dari kekuatan dan kelemahan internal serta kesempatan eksternal dan ancaman dengan melihat faktor internal dan eksternal. Untuk faktor strategi internal dan eksternal yang berdasarkan hasil analisis penilaian penyebaran kuesioner dari pelanggan dan karyawan pada perusahaan Hotel XYZ Kota Tangerang. Hasil analisis Faktor Internal dapat dilihat pada tabel 2 berikut :

Tabel 2

Matriks Internal Factor Evaluation (IFE) Hotel XYZ

\begin{tabular}{|c|c|c|c|}
\hline Faktor Strategi Internal & Bobot & Rating & Skor (Bx R) \\
\hline \multicolumn{4}{|l|}{ Kekuatan } \\
\hline 1. Lingkungan Tenaga Kerja & 0,120 & 4,000 & 0,481 \\
\hline 2. Tata kelola dan Tanggung Jawab sosial & 0,118 & 4,000 & 0,470 \\
\hline 3. Pengetahuan Pasar dan Pelanggan & 0,115 & 3,000 & 0,343 \\
\hline 4. Penyebarluasan Strategi & 0,107 & 3,000 & 0,321 \\
\hline 5. Pengembangan Strategi & 0,101 & 3,000 & 0,303 \\
\hline \multicolumn{4}{|l|}{ Kelemahan } \\
\hline 1. Manajemen Informasi, teknologi informasi, dan pengetahuan & 0,086 & 2,000 & 0,171 \\
\hline 2. Keterlibatan Tenaga Kerja & 0,086 & 2,000 & 0,171 \\
\hline 3. Hubungan dan kepuasan pasar & 0,083 & 2,000 & 0,166 \\
\hline 4. Kepemimpinan senior & 0,078 & 2,000 & 0,156 \\
\hline 5. System Kerja & 0,070 & 1,000 & 0,069 \\
\hline Faktor Strategi Internal & Bobot & Rating & Skor $(\mathbf{B x} \mathbf{R})$ \\
\hline 6. Pengukuran dan Analisis Kinerja Organisasi & 0,064 & 1,000 & 0,064 \\
\hline 7. Proses Kerja & 0,051 & 1,000 & 0,050 \\
\hline Total & 1,000 & & 2,771 \\
\hline
\end{tabular}

Total matrix IFE yang dimiliki oleh Hotel XYZ adalah 2,771, total skor tersebut lebih besar dari nilai rata-rata yaitu 2,5 sehingga menunjukkan bahwa Hotel XYZ mempunyai strategi yang baik dalam memanfaatkan kekuatan internal dan berhasil dalam mengantisipasi kelemahan internal perusahaan. Kekuatan Hotel XYZ yang paling dominan berdasarkan analisis di atas yaitu lingkungan tenaga kerja yang kondusif sehingga pemimpin perusahaan berhasil menciptakan suasana yang baik diantara sesama rekan kerja kemudian disusul dengan tata kelola dan tanggung jawab sosial, menandakan bahwa tanggung jawab perusahaan terhadap masyarakat sekitar sangat baik, perusahaan senantiasa peduli terhadap masyarakat, hal ini sangat baik untuk meningkatkan branding terhadap perusahaan hotel.

Proses kerja menjadi nilai terendah yang harus menjadi perhatian perusahaan, menurut responden banyak terjadi keluhan dalam hal lamanya proses menunggu untuk proses check in sampai dengan masuk kamar, ada yang rusak beberapa fasilitas hotel, buktinya akses wifi yang jelek, kolam renang dan tempat fitness yang masih dalam proses perbaikan, sedikitnya jumlah lift sehingga temu harus mengantri lama dalam penggunaan lift, dan rasa yang disajikan dalam restaurant masih kurang enak rasanya. Beberapa kelemahan tersebut harus segera diantisipasi agar perusahaan dapat meningkatkan kinerja perusahaan.

Analisa faktor eksternal perusahaan Hotel XYZ Kota Tangerang berdasarkan analisa pasar, perusahaan pesaing, keadaan sosial dan pemerintah, pelanggan, dan perekonomian, maka diketahui peluang dan ancaman yang ada di perusahaan. Matriks EFE dapat dilihat pada tabel 3 
Tabel 3.

Matriks Eksternal Factor Evaluation (EFE) Hotel XYZ

Peluang

\section{Faktor Strategi Eksternal}

1. Lokasi yang strategis

2. Banyaknya peluang bisnis yang belum digarap untuk pengadaan ruangan rapar,seminar, dan pernikahan

3. Segmen harga medium yang terus tumbuh

\section{Faktor Strategi Eksternal}

4. Merekrut tenaga kerja yang terampil dari masyarakat sekitar

5. Kebijakan pemerintah daerah Kota Tangerang yang mendukung industri perhotelan

Ancaman

1. Program promosi yang gencar dari perusahaan kompetitor

2. Munculnya hotel baru dengan konsep low cost

3. Perubahan selera konsumen

4. Fasilitas dan pelayanan yang diberikan oleh kompetitor

\section{Bobot}

0,131

0,126

0,121

Bobot

0,115

0,114

0,106

0,098

0,095

0,094
Rating

4,000

3,000

3,000

Rating

3,000

3,000

3,000

0,319

2,000
2,000
1,000

0,196

0,189

0,094 Total

Total matriks EFE yang dimiliki oleh Hotel XYZ adalah sebesar 2,75. Total skor tersebut lebih besar dari nilai rata-rata yaitu 2,5 sehingga menunjukkan hotel XYZ mempunyai strategi yang baik dalam memanfaatkan peluang eksternal dan berhasil dalam menghindari ancaman eksternal perusahaan. Peluang dominan yang menguntungkan bagi Hotel XYZ yaitu lokasi yang strategis dengan skor 0,525. Sedangkan ancaman yang paling dominan dan harus diberikan perhatian serius yaitu program promosi yang gencar dari perusahaan kompetitor dengan skor 0,319 .
Selanjutnya melakukan tahap pencocokan yang merupakan pencarian strategi alternatif bagi Hotel XYZ. Pencarian alternatif strategi mengacu pada hasil penggabungan dari faktor internal dan eksternal Hotel yang telah diteliti. Tahap ini juga merupakan tahap pencocokan yang fokus pada upaya menghasilkan strategi alternatif dan dapat dijalankan dengan memadukan faktor-faktor internal dan eksternal dalam sebuah matriks. sebagaimana disajikan dalam gambar berikut ini.

\section{Total Nilai Faktor Intemal Yang diberi Bobot

Kuat Rata-Rata Lemah \\ $3,0-4,0 \quad 2,0-2,99 \quad 1,0-1,99$}

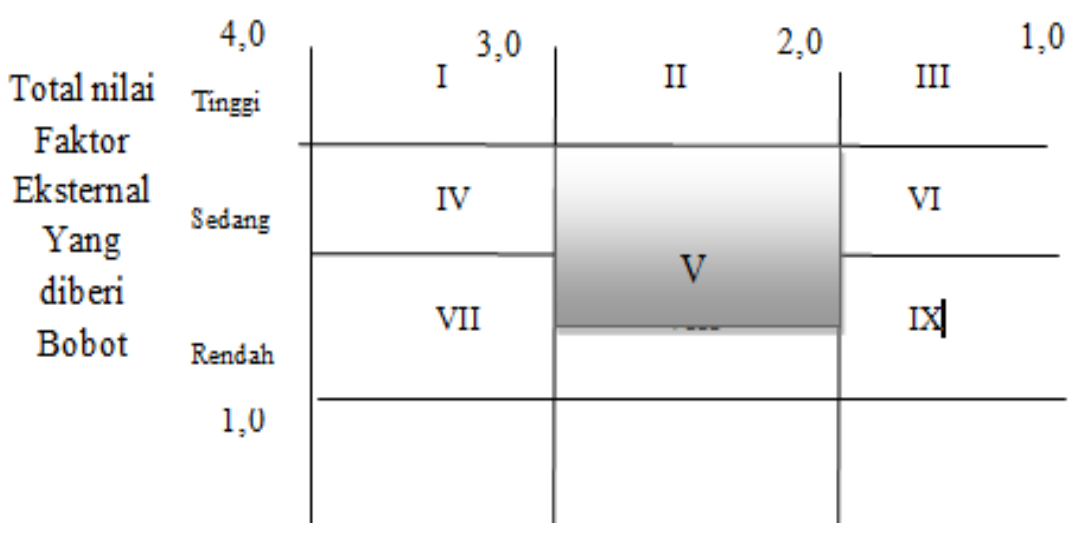

Gambar 1. Matriks Internal-Eksternal Hotel XYZ Kota Tangerang 
Matriks Internal dan ekternal dibagi menjadi tiga bagian utama yang mempunyai dampak alternatif strategis berbeda. Pertama, perusahaan yang masuk ke dalam kuadran I, II, atau IV dapat disebut pertumbuhan. Strategi intensif untuk kuadran ini adalah penetrasi pasar, pengembangan pasar dan pengembangan produk atau integrasi ke belakang, depan, dan horizontal. Kedua, perusahaan yang masuk dalam kuadran III, V, VII paling baik dikelola dengan strategi pertahankan dan pemeliharaan, strategi penetrasi pasar dan pengembangan produk merupakan jenis strategi yang umum untuk jenis perusahaan pada kuadran ini. Ketiga, perusahaan yang masuk ke dalam kuadran VI,VIII, dan IX paling baik dikelola dengan strategi divestasi (David, 2004).

Berdasarkan analisis matriks IFE-EFE yang dipergunakan untuk memetakan strategi bersaing perusahaan, maka penjumlahan skor pembobotan IFE yang menggambarkan kekuatan internal perusahaan pada sumbu $X$ sebesar 2,771 dan penjumlahan skor pembobotan EFE yang menggambarkan daya tarik perusahaan dalam industri pada sumbu Y sebesar 2,752, didapatkan hasil analisis bahwa perusahaan berada pada kuadran V. Berdasarkan hasil tersebut Hotel XYZ berada pada posisi bersaing rata-rata, alternatif strategi yang dapat dilakukan pada posisi tersebut yaitu strategi dengan cara diferensiasi.

Differensiasi membedakan penawaran dari sebuah organisasi dalam sebuah cara yang dianggap oleh pelanggan sebagai penambahan nilai. Diferensiasi dikaitkan dengan adanya keunikan, berdasarkan hasil analisa di atas keunikan yang dimiliki oleh Hotel XYZ adalah memiliki ruang meeting dan ballroom yang sangat luas dan didukung dengan lokasi yang strategis di Kota Tangerang. Hotel XYZ dapat memberikan pengalaman kepada pelanggan dengan menfokuskan diri sebagai meeting and convention hotel.

Pengembangan produk dapat dilakukan dengan cara packaging dan programing, sehingga bagaimana mengemas sebuah produk agar manjadi menarik dan variatif. Paket dan program yang ditawarkan oleh Hotel XYZ dapat lebih variatif contohnya dengan mengadakan international and traditional weeding package, office meeting, family gathering, dan paket event lainnya. Strategi ini dapat lebih intensif jika Hotel XYZ dapat melakukan "jemput bola" kepada calon konsumen, yakni dengan menawarkan produk jasa secara langsung dan berkesinambungan. Beberapa hal yang dapat dilakukan adalah dengan :

1) Menjalin kerja sama dengan Agen Penjualan Hotel On-line, travel agen, maskapai pernerbangan, maupun pengusaha catering.
2) Menjalin kerja sama dengan Pemerintah Daerah, Kementerian dan Swasta untuk penggunaan ruang meeting dan ballroom yang cukup luas dengan membuat diskon paket untuk penggunaan ruang meeting sekaligus menginap di hotel.

3) Menjalin kerja sama dengan event organizer untuk mengadakan acara atau event live musik maupun seminar.

\section{KESIMPULAN \& SARAN}

\section{Kesimpulan}

Total matrix IFE yang dimiliki oleh Hotel XYZ adalah 2,771, total skor tersebut lebih besar dari nilai rata-rata yaitu 2,5 Total matriks EFE yang dimiliki oleh Hotel XYZ adalah sebesar 2,75. Berdasarkan hasil tersebut Hotel XYZ berada pada posisi bersaing rata-rata, Berdasarkan hasil tersebut Hotel XYZ berada pada posisi bersaing rata-rata.

\section{Saran}

Alternatif strategi yang dapat dilakukan pada posisi tersebut yaitu strategi dengan cara diferensiasi, seperti menfokuskan diri sebagai meeting and convention hotel, Pengembangan produk dapat dilakukan dengan cara packaging dan programing dan menawarkan produk jasa secara langsung dan berkesinambungan

\section{DAFTAR PUSTAKA}

Demirbag, Mehmet.Tatoglu, E. Tekinkus, M. \& Zaim,S. 2006. An analysis of the relationship between TQM Implementation and organizational performance evidence from Turkish SMEs. Journal of Manufacturing Technology Management, Vol 17 No 6 : 829847

Fahmi, Irham. 2013. Manajemen Kinerja Teori dan Aplikasi. Bandung : Penerbit Alfabeta.

Fred R. David. 2004. Manajemen Strategis. Buku 1 Edisi 12. Jakarta: Salemba Empat.

Heizer, Jay. \& Barry, Render. 2015. Manajemen Operasi. Jakarta : Penerbit Salemba Empat.

Helfert, Erich. A. 1996. Teknik Analisis Keuangan (Petunjuk Praktis Untuk Mengelola dan Mengukur Kinerja Perusahaan). Edisi 8. Jakarta: Erlangga

Moerdiyanto. 2010. Pengaruh Tingkat Pendidikan Manajer Terhadap Kinerja Perusahaan GOPublic. FISE Universitas Negeri Yogyakarta.

Rivai, V. \& Basri. 2004. Performance Appraisal: Sistem yang tepat untuk menilai kinerja karyawan dan daya saing perusahaan. Jakarta : Prenada Media. 